\title{
Contribution of ARV Treatment in the Correction of Anemia in People Living with HIV during the First Semester in the Hematology Department of Conakry University Hospital
}

\author{
Diakite Mamady ${ }^{1,2 *}{ }^{\mathbb{C}}$, Kante Ansoumane Sayon ${ }^{1,2}$, Keita Fatimata ${ }^{2,3}$, Ouendouno Soumana ${ }^{1}$, \\ Camara Toumin ${ }^{2,4}$, Diallo Abdoul Goudoussy', Kourouma Mamadou', Sylla Mouctar ${ }^{1}$, \\ Camara Fatou1, Awada Mohamed4, Traore Fodé Amara',5, Magassouba Aboubacar Sidiki6, \\ Sidikiba Sidibé6, Abdoulaye Touré 6
}

\author{
${ }^{1}$ Department of Hematology, Conakry University Hospital, Conakry, Guinea \\ ${ }^{2}$ Faculty of Health Sciences and Techniques, Gamal Abdel Nasser University of Conakry, Conakry, Guinea \\ ${ }^{3}$ Department of Dermatology-MST, Conakry University Hospital, Conakry, Guinea \\ ${ }^{4}$ Department of Internal Medicine, Conakry University Hospital, Conakry, Guinea \\ ${ }^{5}$ Department of Infectious and Tropical Diseases, Conakry University Hospital, Conakry, Guinea \\ ${ }^{6}$ Public Health Department, CHU, Conakry, Guinea \\ Email: ^mamadydiankana@yahoo.fr, layesidikiba@gmail.com, abdoulaye.toure@insp-guinee.org
}

How to cite this paper: Mamady, D., Sayon, K.A., Fatimata, K., Soumana, O., Toumin, C., Goudoussy, D.A., Mamadou, K., Mouctar, S., Fatou, C., Mohamed, A., Amara, T.F., Sidiki, M.A., Sidibé, S. and Touré, A. (2021) Contribution of ARV Treatment in the Correction of Anemia in People Living with HIV during the First Semester in the Hematology Department of Conakry University Hospital. World Journal of AIDS, 11, 143-151. https://doi.org/10.4236/wja.2021.114011

Received: August 26, 2021

Accepted: December 4, 2021

Published: December 7, 2021

Copyright $\odot 2021$ by author(s) and Scientific Research Publishing Inc. This work is licensed under the Creative Commons Attribution-NonCommercial International License (CC BY-NC 4.0). http://creativecommons.org/licenses/by-nc/4.0/ (c) (i) (8)

\begin{abstract}
Introduction: Anemia is frequently associated with the natural course of people living with HIV (PLWHIV). The objective was to describe the evolution of anemia in PLWHIV during the first 6 months of ART and to identify the associated factors in the hematology service of the Ignace Deen national hospital of the Conakry University Hospital. Methods: This was a prospective, observational descriptive and analytical study lasting one year from August 1, 2019 to July 31, 2020. It focused on PLWHIV who were newly included in ART during the period of study in the Hematology Department of Ignace Deen Hospital. Results: Of 45 PLWHIV, 40 presented with anemia of $88.89 \%$. The mean age was 40.16 years \pm 12.29 years and extremes of 22 and 71 years. The female sex represented $65 \%$ of cases with a sex ratio of 0.54 . Prolonged fever was the main reason for consultation, $97.5 \%$. The HIV-1 serotype was represented in all anemic patients. At least one OI was found in 24 patients, 60\%. MO anemia was severe (28.9\%), moderate (44.4\%) and mild (26.7\%). At M6 it was moderate $(5.9 \%)$ and light (94.1\%). It was normochromic normocytic in 55\%. At M0, statistical analysis was significant between anemia and OIs, WHO stage
\end{abstract}


and CD4 count, but the link was not established at M6. Conclusion: Anemia is frequently associated with HIV infection linked to delayed treatment. Its development would be better with the establishment of good support. Specific actions should be taken to better identify the factors involved.

\section{Keywords}

PLWHIV, ART, Treatment, Anemia, CHU Conakry

\section{Introduction}

HIV (Human Immunodeficiency Virus) is the cause of acquired immunodeficiency syndrome (AIDS) as well as a large number of biological manifestations which can be responsible for serious haematological disorders affecting all blood lines including erythrocytes, explored by the blood count [1] [2].

Anemia remains one of the most common haematological complications in HIV infection in its AIDS phase [3]. It is defined by a decrease in hemoglobin level below $13 \mathrm{~g} / \mathrm{dl}$ in men and $12 \mathrm{~g} / \mathrm{dl}$ in women [4].

HIV infection is a growing problem of public health, but also of the society; true scourge of the 21st century [5].

In 2018, estimated 37.9 million people were living with HIV worldwide, of which 1.7 million were newly infected, 23.3 million were on antiretroviral therapy and 770,000 deaths from HIV/AIDS-related illnesses [6].

In Africa 25.7 million people were living with HIV, of which 1.3 million were on treatment, bringing the total number of people on antiretroviral therapy to 16.3 million, i.e. a coverage rate of $64 \%$ [7].

In Guinea 130,000 people were infected with HIV in 2014, and only 28,000 (21.54\%) were on ARVs [8].

Hematologic abnormalities in general and anemia in particular in HIV occur in almost all patients as they progress. They are the result of the consequences of immunodeficiency and/or dysregulation of the immune system, complications of infections (bacterial, viral or fungal), side effects of multiple treatments and the direct role of the virus on certain hematopoietic progenitors and blood cells [5].

In the USA, Cosby of the University of California reported an $85 \%$ prevalence of anemia in $146 \mathrm{HIV}$-infected patients [9].

In Zimbabwe, Malyangu reports that during HIV infection, anemia is the most common cytopenia affecting $95.2 \%$ of people [10].

In SENEGAL in 2017, FALL S. et al., reported in their study anemia is in $83.3 \%[11]$.

The biological assessment is a real-time witness on the one hand of the efficacy and tolerance of the treatment and on the other hand of the évolution of the infection [12]. 
In September 2007, the Guinean state made antiretroviral treatment free for PLWHIV/AIDS. However, biological monitoring represents the weak point in the medical care of PLWHIV/AIDS under ARV treatment [13].

We therefore deemed it appropriate to assess the course of anemia at the start of ARV treatment while determining the factors that are likely to be associated.

The objective of this study was to describe the course of anemia in PLWHIV during the first 6 months of ART and to identify the associated factors in the Hematology Department of the Ignace Deen National Hospital.

\section{Material and Methods}

\subsection{Setting and Type of Study}

This was a descriptive prospective study carried out at the Hematology Department of the Ignace Deen National Hospital. The hematology service has a capacity of 35 beds and a unit for the care and psychosocial support of PLWHIV. The unit has two rooms, including a routine consultation room which provides clinical follow-up for patients and a psychosocial consultation room.

\subsection{Population and Study Period}

The study took place over a period of one year from August 1, 2019 to July 31, 2020. It concerned all patients aged at least 18 years, who were admitted for the management of HIV infection. The date of enrollment into the study corresponded to the date of initiation of ARV treatment. Non-consenting patients, those not performing the follow-up assessment and those previously benefiting from ARV treatment were not included.

Each patient was followed for 6 months from the date of initiation of ARV treatment.

\subsection{Collection of Data}

For each patient, the socio-demographic characteristics (age, sex, marital status, origin, profession), clinical (reasons for consultation, history, opportunistic infections, WHO stages at presentation) and biological (virus serotype, CD4 count, hemoglobin level and haematimetric constants) were collected at inclusion. The biological parameters including those of the blood count, CD4 and viral load were collected at 6th month into ART.

Data were collected through the administration of a standardized questionnaire by an interviewer. Sociodemographic and clinical data were collected by direct interview and during the consultation and biological data from laboratory results. The anemias were differentiated according to the erythrocytic constancies namely: The mean globular volume (microcytic, normocytic and macrocytic), the mean corpuscular hemoglobin content (hypochromic, normochromic), but also according to the severity. The severity was stratified into three groups: severe $(\mathrm{Hb}<8 \mathrm{~g} / \mathrm{dl})$, moderate ( $\mathrm{Hb}$ between 8 and $10.5 \mathrm{~g} / \mathrm{dl}$ ) and mild (between 10.5 and $12 \mathrm{~g} / \mathrm{dl})$. 


\subsection{Data Management and Analysis}

The data collected were entered into the Epidata software. The description of the population consisted in calculating the median with the interquartile range for the quantitative variables, of the proportion for the categorical variables.

Comparisons were made with Fisher's exact test for proportions. The significance level was set at 0.05. Analyzes were performed with Statistic Package for Social Sciences (SPSS) software, version 21.

\subsection{Ethical Considerations}

The informed consent of each patient was obtained before their inclusion in the study, confidentiality was required based on anonymity in order to respect their dignity without discrimination.

\section{Results}

A total of 45 patients with a median age of 36 years (interquartile range: 32.0 46.5 years) were included in this study; 29 (64.4\%) were women. Thirty (66.7\%) were singles, while the rest were married or widowed. The patients resided in Conakry in $82.2 \%$ of cases and consisted of civil servants (17.8\%), liberal professions (75.6\%), pupils and students (6.7\%).

Anemia was confirmed in $40(88.9 \%)$ patients, and it was severe in $28.9 \%$. Clinically, the main reasons for consultation were prolonged fever (97.5\%) and headache $(26 \%)$. Of the anemic patients, $60 \%$ were in clinical stage I or II of AIDS according to WHO (Table 1, Table 2).

The patients were all infected with HIV1, on ARV treatment and the treatment regimen was, TDF-3TC-EFV (Tenofovir-Lamivudine-Efavirenz). Their outcomes were as follows: observant (82.5\%), non-observant (2.5\%), lost to follow-up (2.5\%) and died (12.5) at M6.

Factors associated with anemia at the time of inclusion (Table 3) were opportunistic infections, WHO stage of AIDS and decreased CD4 count (P value).

\section{Discussion}

The objective of this study was to describe the course of anemia in PLWHIV during the first 6 months of ARV treatment. It also aimed to analyze the factors associated with the occurrence of anemia in the Hematology Départment of the Ignace Deen National Hospital. The results showed that about nine out of ten people who were new to ARV treatment were anemic. In an earlier study carried out in Guinea [14], the authors had reported a relatively high frequency of anemia of around 54.6\% in PLWHIV. This high frequency of anemia in our study could be explained by the fact that patients are diagnosed late with opportunistic conditions which lead for the most part to anemia regardless of the virus itself which could be another cause. This difference lies in the study population. Their study focused on patients being screened in wards that were not referral for anemia, while our populations were diagnosed in a Hematology Department on 
the occasion of a potentially anemic disease.

The frequency of anemia was significantly elevated in those with multiple opportunistic infections, advanced AIDS, and high viral load. In a study conducted in the DRC in 2014 [15], the results showed that the advanced clinical stage of the infection was a factor favoring anemia. These results confirm the fact that PLWHIV come to our department late but also the possibility, according to the literature, of haematological disturbances during this infection [5]. All of our anemic patients were infected with HIV 1 and the ARV treatment regimen was primarily TDF-3TC-EFV (Tenofovir-Lamuvidine-Efavirenz) to which the vast majority of patients were adherent.

Table 1. Clinical characteristics of anemic patients on Anti-retroviral Treatment (ART) at the hematology service of the Ignace Deen hospital in Conakry 2019-2020.

\begin{tabular}{|c|c|c|}
\hline Clinical Features of Anemic PLWHIV & Workforce $(\mathrm{N}=40)$ & Percentage \% \\
\hline \multicolumn{3}{|l|}{ Reasons for consultation } \\
\hline Prolonged fever & 39 & 97.5 \\
\hline Pallor & 6 & 15.0 \\
\hline Headache & 26 & 65.0 \\
\hline Anorexia & 13 & 32.5 \\
\hline Dizziness & 14 & 35.0 \\
\hline Physical asthenia & 25 & 55.6 \\
\hline Weight loss & 7 & 17.5 \\
\hline \multicolumn{3}{|l|}{ Antecedents } \\
\hline No & 12 & 30 \\
\hline Gastritis & 6 & 15 \\
\hline Hepatitis B & 1 & 2.5 \\
\hline Arterial Hypertension & 3 & 7.5 \\
\hline Tuberculosis & 3 & 7.5 \\
\hline Toxoplasmosis & 1 & 2.5 \\
\hline \multicolumn{3}{|l|}{ The WHO stadium } \\
\hline I - II & 24 & 60.0 \\
\hline III - IV & 16 & 40.0 \\
\hline \multicolumn{3}{|l|}{ Presence of IO } \\
\hline Yes & 24 & 60.0 \\
\hline No & 16 & 40.0 \\
\hline \multicolumn{3}{|l|}{ The number of IOs } \\
\hline$\leq 1$ & 11 & 45.83 \\
\hline 2 and more & 13 & 54.16 \\
\hline
\end{tabular}


Table 2. Biological characteristics of anemic patients under Anti-retroviral Treatment (ART) at the hematology service of the Ignace Deen hospital in Conakry 2019-2020.

\begin{tabular}{|c|c|c|}
\hline \multirow{2}{*}{ Characteristics } & Mo & M6 \\
\hline & Effective/(\%) & Effective/(\%) \\
\hline \multicolumn{3}{|c|}{$\mathrm{CD} 4$ at $\mathrm{M} 0$ and $\mathrm{M} 6$} \\
\hline Average & 518.52 & 744.37 \\
\hline \multicolumn{3}{|c|}{ Viral load (copies/ml) at M0 and M6 } \\
\hline Mean & 69363.22 & 4473.13 \\
\hline \multicolumn{3}{|l|}{ Hemoglobin level } \\
\hline$<8$ & $13(28.9)$ & $0(0.0)$ \\
\hline $8-10.5$ & $20(44.4)$ & $2(5.89)$ \\
\hline $10.5-12$ & $7(26.7)$ & $16(47.06)$ \\
\hline Not anemic & $0(0.0)$ & $16(47.06)$ \\
\hline Average & 9.442 & 12.106 \\
\hline Normocytic Normochromic & $22(55.0)$ & $17(94.44)$ \\
\hline Microcytic Hypochromic & $10(25.0)$ & $0(0.0)$ \\
\hline Normocytic Hypochromic & $6(15.0)$ & $0(0.0)$ \\
\hline Microcytic Normochrome & $2(5.0)$ & $1(5.56)$ \\
\hline
\end{tabular}

Table 3. Correlation between anemia and age, OIS, WHO stage, viral load and CD4 to m6 count in anemic patients under Anti-Retroviral Treatment (ARV) in the hematology service of the Ignace Deen hospital in Conakry 2019-2020.

\begin{tabular}{|c|c|c|c|c|c|c|}
\hline \multirow{2}{*}{\multicolumn{2}{|c|}{ Characteristics }} & \multirow{2}{*}{ Anemic } & \multirow{2}{*}{ Not anemic } & \multirow{2}{*}{ Total } & \multicolumn{2}{|c|}{ P Value } \\
\hline & & & & & Mo & M6 \\
\hline \multirow{3}{*}{ Age } & 22 - 35 years & $7(50 \%)$ & $7(50 \%)$ & $14(100.0)$ & \multirow{3}{*}{0.98} & \multirow{3}{*}{1.00} \\
\hline & $36-45$ years & $7(53.8 \%)$ & $6(46.2 \%)$ & $13(100.0)$ & & \\
\hline & 45 years and over & $4(57.1 \%)$ & $3(42.9 \%)$ & $7(100.0)$ & & \\
\hline \multirow{2}{*}{ IO } & $\leq 1 \mathrm{IO}$ & $3(42.86 \%)$ & $4(57.14 \%)$ & $7(100.0)$ & \multirow{2}{*}{0.05} & \multirow{2}{*}{0.69} \\
\hline & $2-3 \mathrm{IO}$ & $5(62.5)$ & $3(37.7 \%)$ & $8(100.0)$ & & \\
\hline \multirow{4}{*}{$\begin{array}{l}\text { WHO } \\
\text { stages }\end{array}$} & Stage I & $10(52.6 \%)$ & $9(47.4 \%)$ & $19(100.0)$ & \multirow{4}{*}{0.01} & \multirow{4}{*}{0.47} \\
\hline & Stage II & $2(40.0 \%)$ & $3(60.0 \%)$ & $5(100.0)$ & & \\
\hline & Stage III & $3(42.9 \%)$ & $4(57.1 \%)$ & $7(100.0)$ & & \\
\hline & Stage IV & $3(100.0 \%)$ & $0(0.0 \%)$ & $3(100.0)$ & & \\
\hline \multirow{2}{*}{ Viral load } & $\leq 100,000$ copies & $8(33.3 \%)$ & $16(66.7 \%)$ & $24(100)$ & \multirow{2}{*}{0.08} & \multirow{2}{*}{0.71} \\
\hline & $>100,000$ copies & $5(50.0 \%)$ & $5(50.0 \%)$ & $10(100.0)$ & & \\
\hline \multirow{2}{*}{$\begin{array}{l}\text { CD4 } \\
\text { count }\end{array}$} & $\leq 500$ & $12(48.0 \%)$ & $13(52.0 \%$ & $25(100.0)$ & \multirow{2}{*}{0.01} & \multirow{2}{*}{0.68} \\
\hline & $>500$ & $5(62.5 \%)$ & $3(37.5 \%)$ & $8(100.0)$ & & \\
\hline
\end{tabular}


We found that about a third of the patients presented with severe anemia. It was mainly normochromic normocytic anemia, the course of which was marked by a quasi-normalization of the mean hemoglobin level at the end of the six months of treatment. A study conducted in India [16] had reported predominance of normocytic normochromic anemia in PLWHIV. Another study conducted in Burkina had found a significant rise in hemoglobin levels [12]. Anemia with its signs of decompensation remains the reasons leading the patient to consult especially in a hematology service. This regression of anemia observed in our study could be explained by the quality of the patient care in the hematology service of the Ignace Deen Hospital but also the undoubtedly effectiveness of the ARV treatment and the treatments administered against opportunistic diseases.

This study could have some limitations. These are mainly the low sample size. However, the prospective nature of the study made it possible to collect quality data, the results of which will make it possible to formulate recommendations for improving the quality of patient care.

In conclusion, anemia is frequently associated with HIV infection linked to delayed treatment. Its development would be better with the establishment of good support. Specific actions should be taken to better identify the factors involved.

\section{Contributions from the Authors}

The authors contributed at one or more levels of the drafting of the manuscript from the protocol, the data collection, the drafting itself. They have all read and approved the final manuscript.

\section{Acknowledgements}

Our thanks to the place:

- Staff from the PLWHIV care unit of the hematology service of the Ignace Deen National Hospital of the CJU in Conakry;

- From the African Center of Excellence for the Prevention and Control of Communicable Diseases (CEA-PCMT);

- From the Guinea Infectious Disease Research and Training Center (CERFIG);

- From the Faculty of Health Sciences and Techniques of Gamal Abdel Nasser University in Conakry (FSTS/UGANC);

\section{Conflicts of Interest}

The authors declare no conflicts of interest regarding the publication of this paper.

\section{References}

[1] Diakite, M., Kone, A., Kante, A.S., Sangare, M., Traore, C., Adjambri, A.S., Yayo, A.M., Latte, T. and Sawadogo, D. (2017) Quantitative and Morphological Anomalies of the Hemogram in Clients Received at the CDV Unit of the Central Laboratory of Yopougon University Hospital. Mali Medical, 3, 28-33. 
[2] OuédraogoYugbaré, S.O., Zagré, N., Koueta, F., Dao, L., Kam, L., Ouattara, D.Y. and Simporé, J. (2015) Effectiveness of the Prevention of Mother-to-Child Transmission of the Human Immunodeficiency Virus by the 2010 Protocol of the World Health Organization at the Saint Camille Medical Center in Ouagadougou (Burkina Faso). The Pan African Medical Journal, 22, Article No. 303.

[3] Mocroft, A., Kirk, O., Barton, S.E., Dietrich, M., Proenca, R., Colebunders, R., Pradier, C., Arminio Monforte, A., Ledergerber, B. and Lundgren, J.D. (1999) Anaemia Is an Independent Predictive Marker for Clinical Prognosis in HIV-Infected Patients from across Europe. AIDS, 13, 943-950.

https://doi.org/10.1097/00002030-199905280-00010

[4] Cappellini, M.D. and Motta, I. (2015) Anemia in Clinical Practice-Definition and Classification: Does Hemoglobin Change With Aging? Seminars in Hematology, 52, 261-269. https://doi.org/10.1053/j.seminhematol.2015.07.006

[5] Boni-Cissé, C., Meité, S., Faye-Ketté, H., Sawadogo, D., Latte, T., Dosso, M. and Sangaré, A. (2008) Study of the Hematological Profile Corresponded to the Immunological Profile of Children Infected with HIV Followed at Yopougon CHU in 2006. Mali Medical, 5, 12-17.

[6] World Report 2020: Act Now-To Combat Deep Inequalities and End Pandemics.

[7] WHO (2020) The Work of the World Health Organization in the African Region: Report of the Regional Director: 1 July 2019-30 June 2020.

[8] Ndawinz, J.D.A., Cissé, M., Diallo, M.S.K., Sidibé, C.T. and D’Ortenzio, E. (2015) Prevention of HIV Spread during the Ebola Outbreak in Guinea. The Lancet, 385, 1393. https://doi.org/10.1016/S0140-6736(15)60713-9

[9] Cosby, C., Holzemer, W.L., Henry, S.B. and Portillo, C.J. (2000) Hematological Complications and Quality of Life in Hospitalized AIDS Patients. AIDS Patient Care and STDs, 14, 269-279. https://doi.org/10.1089/108729100317731

[10] Malyangu, E., Abayomi, E.A., Adewuyi, J. and Coutts, A.M. (2000) AIDS Is Now the Commonest Clinical Condition Associated with Multilineage Blood Cytopenia in a Central Referral Hospital in Zimbabwe. Central African Journal of Medicine, 46, 59-61. https://doi.org/10.4314/cajm.v46i3.8525

[11] Fall, S., Djiba, B., Diagne, N., Ndiaye, M., Dieng, F., Kyelem, E.M.C. and Ndiaye, F.S.D. (2017) Profile of Haematological Manifestations of HIV Infection in Adults: Single-Center Study of 262 Senegalese Observations. African Journal of Internal Medicine, 4, 33-36.

[12] Karfo, R., Kabré, E., Coulibaly, L., Diatto, G., Sakande, J. and Sangare, L. (2018) Evolution of Biochemical and Hematological Parameters in People Living with HIV/ AIDS under Antiretroviral Treatment at Camp General Aboubacar Sangoule Lamizana Medical Center (CMCGASL). The Pan African Medical Journal, 29, Article No. 159.

[13] Institut National de la Statistique Ministère du Plan Conakry, Guinée (2013) Enquête Demographique et de Santé et à Indicateurs Multiples (EDS-MICS). https://dhsprogram.com/pubs/pdf/FR280/FR280.pdf

[14] Loua, A., Dramou, C.D., Haba, N.Y., Magassouba, F.B., Lamah, M., Camara, A., Cissé, M., Loua, K.M., Gamy, É.P. and Troussard, X. (2011) Haematological Profile of Patients Infected with HIV in Conakry. Hematologie, 17, 365-369.

[15] Mwadianvita, C.K., Ilunga, E.K., Djouma, J., Wembonyama, C.W., Mutomb, F.M.A., Ekwalanga, M.B., Kabongo, J., Mundongo, H., Mupoya, K., Wembonyama, S., Kalenga Mwenze, P. and Nkoy, A.M.A. (2014) Study of Anemia in HIV Positive Children Naive to Antiretroviral Treatment in Lubumbashi, Democratic Republic of Con- 
go. The Pan African Medical Journal, 17, Article No. 46.

[16] Patwardhan, M.S., Golwilkar, A.S., Abhyankar, J.R. and Atre, M.C. (2002) Hematological Profile of HIV Positive Patients. Indian Journal of Pathology \& Microbiology, 45, 147-150. 